\title{
Facile Synthesis of Ultrastable Fluorescent Copper Nanoclusters and Their Cellular Imaging Application
}

\author{
Wei Yan ${ }^{1}$, Jianqiao Zhang ${ }^{2}$, Muhammad Abbas ${ }^{3,+}{ }^{-0}$, Yulian Li ${ }^{2}$, Syed Zajif Hussain ${ }^{3}$, \\ Shazia Mumtaz ${ }^{3}$, Zhengwei Song ${ }^{1}$, Irshad Hussain ${ }^{3, *}$ and Bien Tan ${ }^{2, *}$ \\ 1 Ministry-of-Education Key Laboratory for the Green Preparation and Application of Functional Materials, \\ Hubei Collaborative Innovation Center for Advanced Organic Chemical Materials, Hubei Key Laboratory of \\ Polymer Materials, Faculty of Materials Science and Engineering, Hubei University, Wuhan 430062, China; \\ willieyancn2003@foxmail.com (W.Y.); songkukus@163.com (Z.S.) \\ 2 Key Laboratory of Material Chemistry for Energy Conversion and Storage, Ministry of Education, \\ School of Chemistry and Chemical Engineering, Huazhong University of Science and Technology, \\ Wuhan 430074, China; jqzhang1991@163.com (J.Z.); yulianli1993@163.com (Y.L.) \\ 3 Department of Chemistry \& Chemical Engineering, SBA School of Science \& Engineering, \\ Lahore University of Management Sciences(LUMS), Lahore 54792, Pakistan; Abbas@UTDallas.edu (M.A.); \\ syed.hussain@lums.edu.pk (S.Z.H.); shaziamumtaz5@gmail.com (S.M.) \\ * Correspondence: ihussain@lums.edu.pk (I.H.); bien.tan@mail.hust.edu.cn (B.T.); \\ Tel.: +86-27-8755-8172 (B.T.); Fax: +86-27-87544532 (B.T.) \\ + Muhammad Abbas is in Department of Chemistry and Biochemistry, University of Texas now.
}

Received: 1 August 2020; Accepted: 25 August 2020; Published: 26 August 2020

check for updates

\begin{abstract}
Copper nanoclusters (Cu NCs) are generally formed by several to dozens of atoms. Because of wide range of raw materials and cheap prices, $\mathrm{Cu}$ NCs have attracted scientists' special attention. However, $\mathrm{Cu}$ NCs tend to undergo oxidation easily. Thus, there is a dire need to develop a synthetic protocol for preparing fluorescent $\mathrm{Cu}$ NCs with high QY and better stability. Herein, we report a one-step method for preparing stable blue-green fluorescent copper nanoclusters using glutathione (GSH) as both a reducing agent and a stabilizing agent. High-resolution transmission electron microscopy (HRTEM), X-ray photoelectron spectroscopy (XPS) and electrospray ionization mass spectrometer (ESI-MS) were used to characterize the resulting Cu NCs. The as-prepared $\mathrm{Cu}$ NCs@GSH possess an ultrasmall size $(2.3 \pm 0.4 \mathrm{~nm})$, blue-green fluorescence with decent quantum yield (6.2\%) and good stability. MTT results clearly suggest that the Cu NCs@GSH are biocompatible. After incubated with EB-labeled HEK293T cells, the Cu NCs mainly accumulated in nuclei of the cells, suggesting that the as-prepared $\mathrm{Cu}$ NCs could potentially be used as the fluorescent probe for applications in cellular imaging.
\end{abstract}

Keywords: copper nanoclusters; glutathione; cellular imaging; fluorescence

\section{Introduction}

Due to their unique physicochemical properties, metal nanoclusters (M NCs) possess promising applications in the field of catalysis [1-3], sensors [4-7], photonics [8,9] and bioimaging [10-13]. With the size of nanoparticles decreasing down to the Fermi wavelength of an electron, the ultrafine particles are envisioned to bridge the "missing link" between metal atoms (showing special optical properties) and nanoparticles (showing surface Plasmon resonance), displaying molecule-like properties such as the strong fluorescence $[14,15]$. Compared with quantum dots (large size and high toxicity), lanthanide-doped nanomaterials (low luminescence efficiency) and organic dyes (poor photostability) [16,17], fluorescent nanoclusters exhibit many advantages including ultrasmall size, good photostability, low toxicity, good biocompatibility, which make them more attractive in the 
biological field [18-20]. Up to date, fluorescent gold and silver nanoclusters were widely explored while copper nanoclusters ( $\mathrm{Cu} \mathrm{NCs)} \mathrm{are} \mathrm{much} \mathrm{less} \mathrm{explored} \mathrm{mainly} \mathrm{because} \mathrm{of} \mathrm{the} \mathrm{difficulty} \mathrm{in} \mathrm{obtaining}$ ultra-small size $\mathrm{Cu}$ NCs with good stability [2,21-23]. However, the great potential advantages over other nanoclusters including abundant available resources and comparable low cost intrigued more research interest. Chemical reduction and the ligand etching method are generally used for the preparation of $\mathrm{Cu}$ NCs [23-27], but they suffer from obvious drawbacks including complicated and time-consuming process, low quantum yield (QY) and poor stability. Using 4-aminothiophenol (PATP) as the thiol capping ligands and reducing agent, Feng et al. prepared $\mathrm{Cu}$ NCs. The QY of the obtained $\mathrm{Cu}$ NCs is as high as $24.6 \%$, but the lifetime is only 14 days [17]. Ouyang et al. succeeded in synthesizing fluorescent $\mathrm{Cu}$ NCs using DNA as template. The QY is as high as $12 \%$, however the fluorescence intensity begin to decrease just after $165 \mathrm{~min}$ [28]. Therefore, there is a dire need to develop a synthetic protocol for preparing fluorescent $\mathrm{Cu}$ NCs with high QY and better stability that can easily be upscaled. Many teams carried out research on $\mathrm{Cu}$ NCs in the bio-system to solve this problem [29-34]. J.C. Hao et al. induce the glutathione-capped CuNCs (GSH-CuNCs) and formed ordered assemblies, resulting in enhanced fluorescent properties [29]. L.Y. Lin used glutathione-capped CuNCs (with QY 1.3\%) to detect $\mathrm{Zn}^{2+}$ basing on the aggregation-induced emission enhancement of GSH-capped Cu NCs [30]. However, both methods used in these literature synthesized CuNCs at room temperature with short-time heating. Although the synthesized CuNCs have close to red fluorescence, the low quantum fluorescence efficiency and poor stability limit their further application.

Herein, a simple one-pot thermo-reduced method is designed to prepare fluorescent $\mathrm{Cu}$ NCs employing glutathione (GSH) as a reducing agent and a protecting agent. In a typical experiment, GSH was first mixed with $\mathrm{CuCl}_{2}$, then $\mathrm{NaOH}$ solution was added, after stirring for $24 \mathrm{~h}$, the solution was cooled down to room temperature. The resulting concentrated Cu NCs@GSH were precipitated by addition of isopropanol and after three purification cycles, and finally the Cu NCs@GSH were dispersed in water for further application. The effect of various synthetic parameters including the concentration of GSH, NaOH, reaction temperature and the reaction time on the fluorescence and stability of the $\mathrm{Cu}$ NCs were examined as optimization. The resulting $\mathrm{Cu}$ NCs were thoroughly characterized by high-resolution transmission electron microscopy (HRTEM), X-ray photoelectron spectroscopy (XPS) and electrospray ionization mass spectrometer (ESI-MS). The as-synthesized $\mathrm{Cu}$ NCs exhibited high QY (6.2\%) and excellent stability (ion-stability, antioxidation stability, photostability and time-stability) and were successfully used for the imaging of HEK293T cells.

\section{Materials and Methods}

\subsection{Reagents and Chemicals}

All the chemical reagents used are at least of analytical grade. Anhydrous copper chloride $\left(\mathrm{CuCl}_{2}\right)$ and glutathione (reduced) (GSH, 98\%) were purchased from Sigma-Aldrich (Shanghai, China). Sodium hydroxide ( $\mathrm{NaOH}, 99.5 \%)$ was bought from National Medicines Corporation, Ltd. of P.R. (Shanghai, China). The HeLa cells and human embryonic kidney cells HEK293T were purchased from the Shanghai Institute of Cells (Shanghai, China). Dimethyl sulfoxide (DMSO, 99\%), 3-(4,5-dimethyl-2-thiazol-2-yl)-2,5-diphenyltetrazolium bromide (MTT, 98\%) and ethidium bromide (EB) were obtained from J\&K Chemicals (Shanghai, China). Dulbecco's modified Eagle's medium (DMEM) was purchased from Gibco (Shanghai, China). The ultrapure water $(\geq 18 \mathrm{M} \Omega$ ) obtained from a Milli-Q water purification system (Darmstadt, German) was used throughout.

\subsection{Characterization}

The fluorescence spectra were measured with an Enspire Multimode Plate Reader (PerkinElmer, Shanghai, China). The optical adsorption spectra were recorded on an UV2550 Spectrophotometer (SHIMADZU, Shanghai, China). High-resolution transmission electron microscopy (HRTEM) images were obtained with a Tecnai $\mathrm{G}^{2} \mathrm{~F} 30$ (FEI, Shanghai, China) at an accelerating voltage of $200 \mathrm{kV}$. The X-ray 
photoelectron spectroscopy (XPS) were measured by AXIS-ULTRA DLD (Shimadzu, Shanghai, China). The mass spectra were obtained with a micro TOF-Q electrospray ionization mass spectrometer (ESI-MS) (Bruker Daltonics, Shanghai, China). The optical density (OD) of the mixture was measured at $490 \mathrm{~nm}$ with a microplate absorbance reader (VersaMax (Molecular Devices), Shanghai, China). Cellular imaging was performed on a Confocal microscope (Olympus IX 81 + FV1000, Shanghai, China) using an excitation wavelength of $380 \mathrm{~nm}$. All the experiments were conducted at room temperature, if not stated otherwise.

\subsection{Synthesis of Blue-Green-Emitting Cu NCs@GSH}

The GSH-stabilized CuNCs were prepared by a thermo-reduced method. In a typical experiment, GSH $(1 \mathrm{~mL}, 9 \mathrm{mM})$ was mixed with $\mathrm{CuCl}_{2}(8.9 \mathrm{~mL}, 50 \mathrm{mM})$, and the solution became cloudy. Next, $\mathrm{NaOH}$ solution $(100 \mu \mathrm{L}, 1 \mathrm{M})$ was added dropwise with vigorous stirring until the mixture solution changed to be clear. Then the mixture was kept stirring at $80{ }^{\circ} \mathrm{C}$ for $24 \mathrm{~h}$ until the color changed from pale blue to purple. The purple solution of $\mathrm{Cu}$ NCs was then gradually cooled down to room temperature and stored in refrigerator at $4{ }^{\circ} \mathrm{C}$. The resulting concentrated Cu NCs@GSH were precipitated by addition of isopropanol, collected through centrifugal at 10,000 rpm, and then redispersed in water. After 3 purification cycles, and finally the Cu NCs@GSH were dispersed in $10 \mathrm{~mL}$ water for further application.

\subsection{Cell Culture and Cytotoxicity Assay}

HeLa cells were cultured in Dulbecco's modified Eagle's medium (DMEM) including high glucose supplemented with $10 \%$ fetal bovine serum (FBS), $100 \mathrm{U}$ of penicillin and $100-\mu \mathrm{g} / \mathrm{mL}$ streptomycin at $5 \% \mathrm{CO}_{2}, 37^{\circ} \mathrm{C}$. The cell viability was determined by the MTT assay according to the manufacturer's instructions. Briefly, the HeLa cells were seeded in a 96-well plate in cell medium overnight. After being incubated with different concentrations of Cu NCs@GSH $(0,10,50,100,200$ and $400 \mu \mathrm{g} / \mathrm{mL})$ for 12 h, $10 \mu \mathrm{L}$ of MTT solution ( $5 \mathrm{mg} / \mathrm{mL}$ ) was added to each well. After $4 \mathrm{~h}$ of incubation, $100 \mu \mathrm{L}$ of DMSO was added to each well. The CuNCs@GSH are synthesized in aqueous phase, whose solubility depends on the ligand GSH. Moreover, the solubility of GSH is $500 \mathrm{~g} / \mathrm{L}$ at $\mathrm{pH}$ 8.0-8.5.

\subsection{Cellular Imaging}

The human embryonic kidney cells HEK293T were grown in DMEM supplemented with 10\% FBS at $37^{\circ} \mathrm{C}$ and $5 \% \mathrm{CO}_{2}$ for $24 \mathrm{~h}$. The cells were then washed with phosphate-buffered saline (PBS), followed by incubation with Cu NCs $(100 \mu \mathrm{L}, 250 \mu \mathrm{g} / \mathrm{mL})$ for $2 \mathrm{~h}$ at $37^{\circ} \mathrm{C}$ and then washed with PBS three times, followed by incubation with EB solution $(100 \mu \mathrm{L}, 2 \mu \mathrm{g} / \mathrm{mL})$ for $15 \mathrm{~min}$. Cellular imaging was then performed on a Confocal microscope (Olympus IX 81 + FV1000) using an excitation wavelength of $380 \mathrm{~nm}$ and $583 \mathrm{~nm}$ after the cells were washed with PBS three times.

\section{Results}

\subsection{Synthesis of Cu NCs@GSH}

The GSH-stabilized blue-green fluorescent $\mathrm{Cu}$ NCs were prepared according to Scheme 1. The as-synthesized $\mathrm{Cu}$ NCs exhibited decent quantum yield ( $Q Y=6.2 \%$ with quinine sulfate in $1-\mathrm{M}$ $\mathrm{H}_{2} \mathrm{SO}_{4}$ as a reference) and excellent stability. The GSH was chosen as both the scaffold and reducing agent to protect the clusters possibly due to the strong interaction of the $\mathrm{Cu}^{2+}$ and appropriately placed cysteine residues in GSH during the encapsulation process [35-37]. Due to the biocompatibility of GSH, GSH-functionalized Cu NCs were found to be suitable for bio-applications due to their bioactive surface. This synthetic method can be categorized as a green one because no toxic chemical/solvent was used in this synthesis process and the reduction was induced thermally in the presence of GSH to produce $\mathrm{Cu}$ NCs@GSH, which were then used for cellular imaging. It is worth noticing that the reaction can be easily upscaled to produce more than $750 \mathrm{~mL} \mathrm{Cu} \mathrm{NCs} \mathrm{in} \mathrm{a} \mathrm{single} \mathrm{synthesis} \mathrm{step} \mathrm{with} \mathrm{decent}$ 
fluorescence emission (Figure S1), which demonstrates the cost-effective and large-scale production of fluorescent metal nanoclusters.

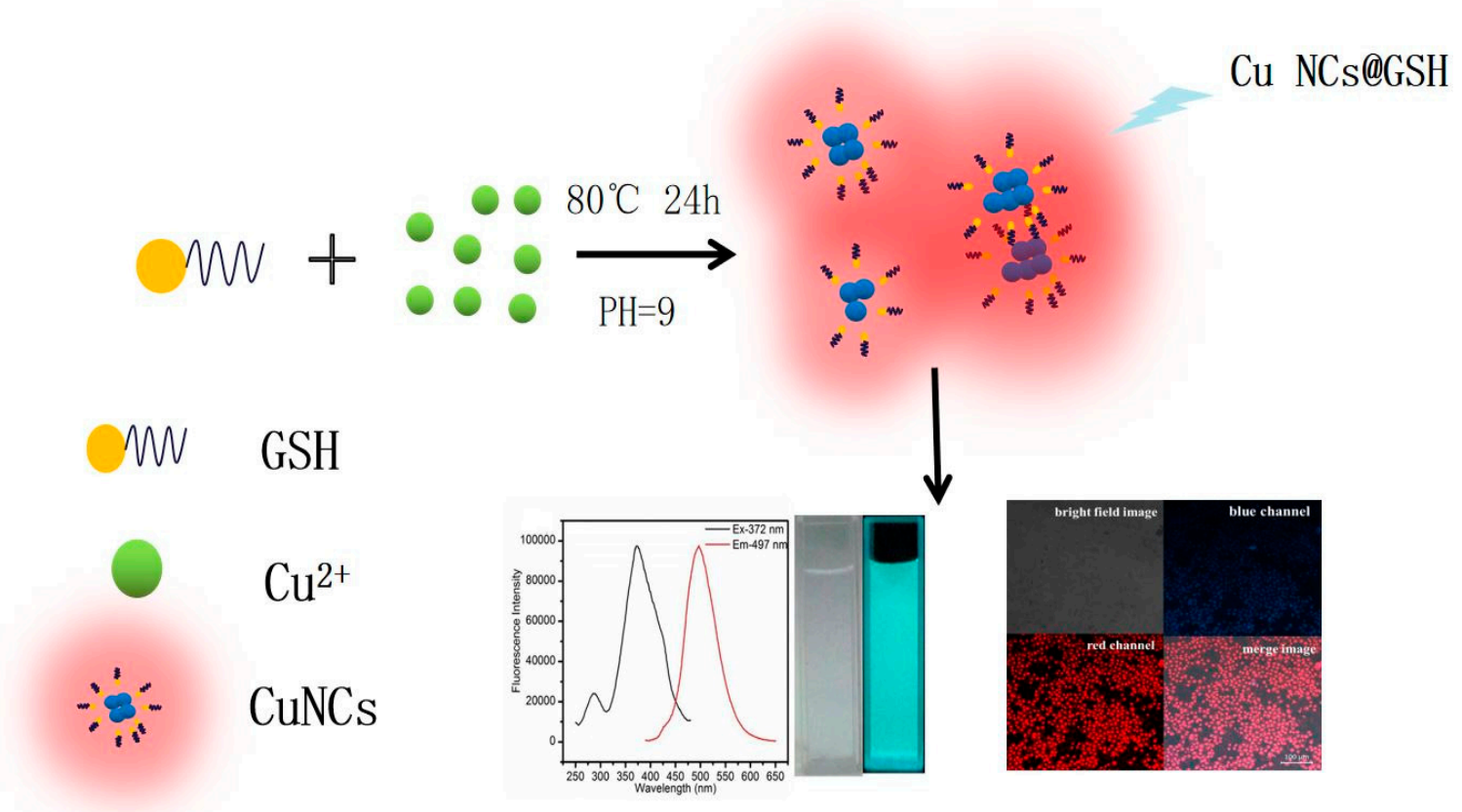

Scheme 1. Schematic illustration of thermo-reduced synthesis of fluorescent Cu NCs@GSH.

\subsection{Optimization Results for Reaction Conditions}

We examined the effect of various synthetic parameters to produce highly fluorescent and stable $\mathrm{Cu}$ NCs including the concentration of $\mathrm{GSH}, \mathrm{NaOH}$, reaction temperature and the reaction time. In the systematic optimization process, the volume of GSH $(1 \mathrm{~mL}), \mathrm{CuCl}_{2}(8.9 \mathrm{~mL}), \mathrm{NaOH}(0.1 \mathrm{~mL})$ were kept constant to keep the same total volume, i.e., $10 \mathrm{~mL}$, for each optimization reaction, the variation parameter was concentration. Firstly, we examined the effect of concentration of GSH to produce stable and fluorescent $\mathrm{Cu}$ NCs. As shown in Figure 1A,B, it was observed that with an increase in the concentration of GSH, the fluorescence intensity of maximum emission peak at $497 \mathrm{~nm}$ increased sharply and then decreased slowly while the color of solution turned from brown to purple and finally to little green (the absorption spectra are shown in Figure S7), which may be due to the lower concentration of GSH that was not sufficient to protect $\mathrm{Cu}$ NCs well. At higher concentration of GSH, the nucleation of the $\mathrm{Cu}$ NCs was trapped by the capping reagent, which reduced the chance of collision and prevented the NCs from growing [38]. Hence, by controlling the amount of GSH, the blue-green (maximum emission wavelength at $497 \mathrm{~nm}$ ) fluorescent $\mathrm{Cu}$ NCs@GSH can be obtained and the highest blue-green fluorescence intensity was achieved by using 9-mM GSH. The final concentration of GSH is $0.9 \mathrm{mM}$. $\mathrm{NaOH}$ was not only helpful to make the cloudy suspension of $\mathrm{GSH}$ and $\mathrm{Cu}^{2+}$ clear, but it can also enhance the reducing capability of -SH of GSH [24]. In Figure 1C, the highest fluorescence intensity of $\mathrm{Cu}$ NCs was achieved when the concentration of $\mathrm{NaOH}$ was $1 \mathrm{M}$. The final concentration of $\mathrm{NaOH}$ is $10 \mathrm{mM}$. The lower $(0.25 \mathrm{M}, 0.5 \mathrm{M})$ and higher concentrations $(2 \mathrm{M}, 4 \mathrm{M})$ of $\mathrm{NaOH}$ were not helpful to further improve fluorescence intensity of $\mathrm{Cu}$ NCs. We also investigated the effect of temperature and reaction time to obtain the most stable and highly fluorescent $\mathrm{Cu}$ NCs. Figure 1D shows the effect of temperature on the fluorescence intensity of $\mathrm{Cu}$ NCs at the prolonged reaction time. Figures 1D and 2 also show that $80^{\circ} \mathrm{C}$ is the optimum temperature for the synthesis of highly fluorescent $\mathrm{Cu}$ NCs. It may due to the fact that a high temperature is not only helpful to overcome the energy barrier of the reduction process, but is also helpful to enhance the reaction rate of both NCs growth and digestion, therefore facilitating the structure optimization of $\mathrm{Cu}$ NCs [1,39-42]. The reducing ability of GSH at lower/room temperature $\left(25^{\circ} \mathrm{C}\right)$ was too low to achieve a decent yield of $\mathrm{Cu}$ NCs due to the slow 
reaction kinetics. However, by increasing the reaction temperature to $90{ }^{\circ} \mathrm{C}$ resulted in the drop of fluorescence intensity, which may be attributed to the aggregation of the ultrasmall $\mathrm{Cu}$ NCs into larger $\mathrm{Cu}$ NPs at higher temperature.

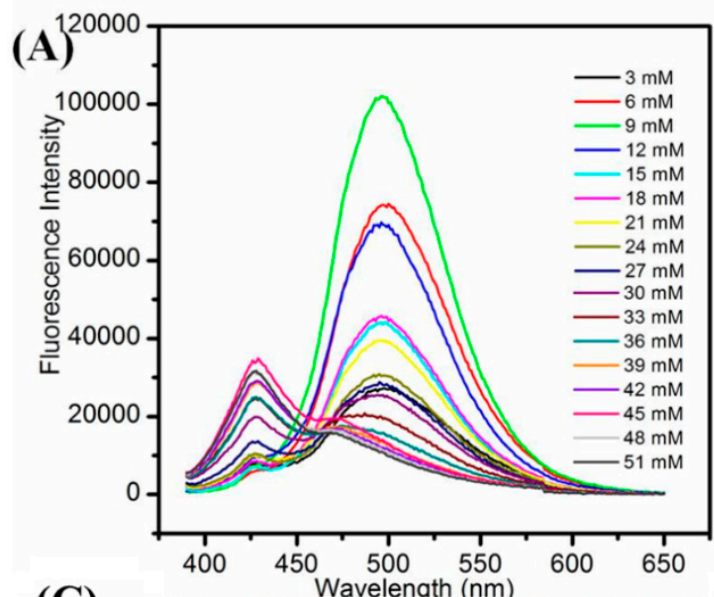

(C)
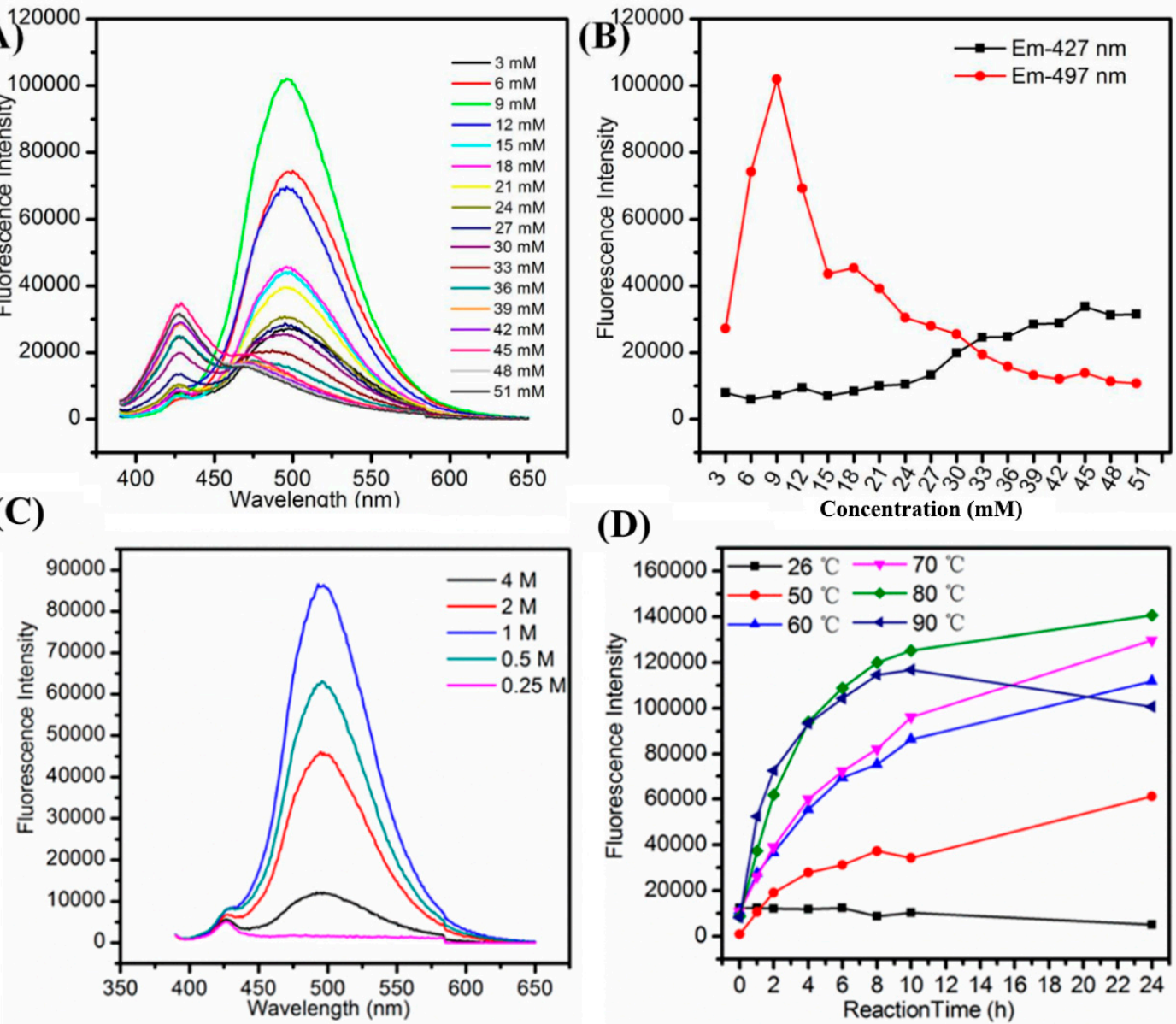

(D)

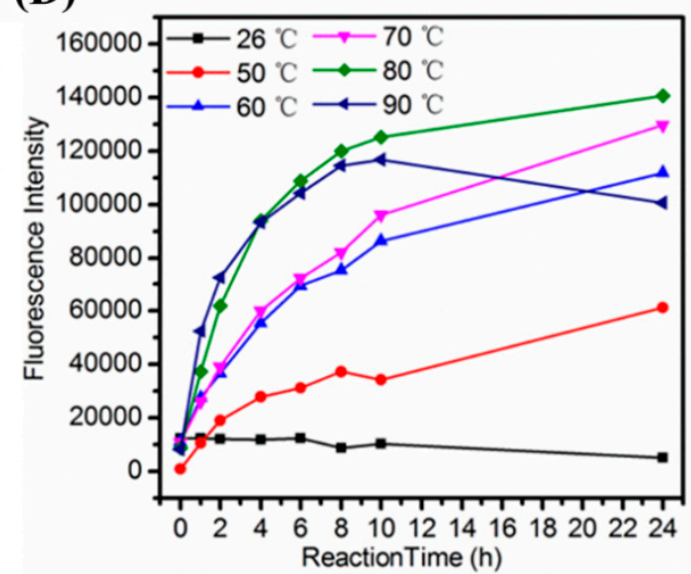

Figure 1. (A) Fluorescence emission wavelength; (B) trend of fluorescence intensity of the emission peak at $497 \mathrm{~nm}$ and $427 \mathrm{~nm}$ of Cu NCs@GSH prepared with increasing concentration of GSH from $3 \mathrm{mM}$ to $51 \mathrm{mM}$; (C) fluorescence emission wavelength of Cu NCs@GSH in the presence of different concentration of $\mathrm{NaOH}$; (D) trend of fluorescence intensity of $\mathrm{Cu}$ NCs@GSH obtained at different temperatures and reaction time. 

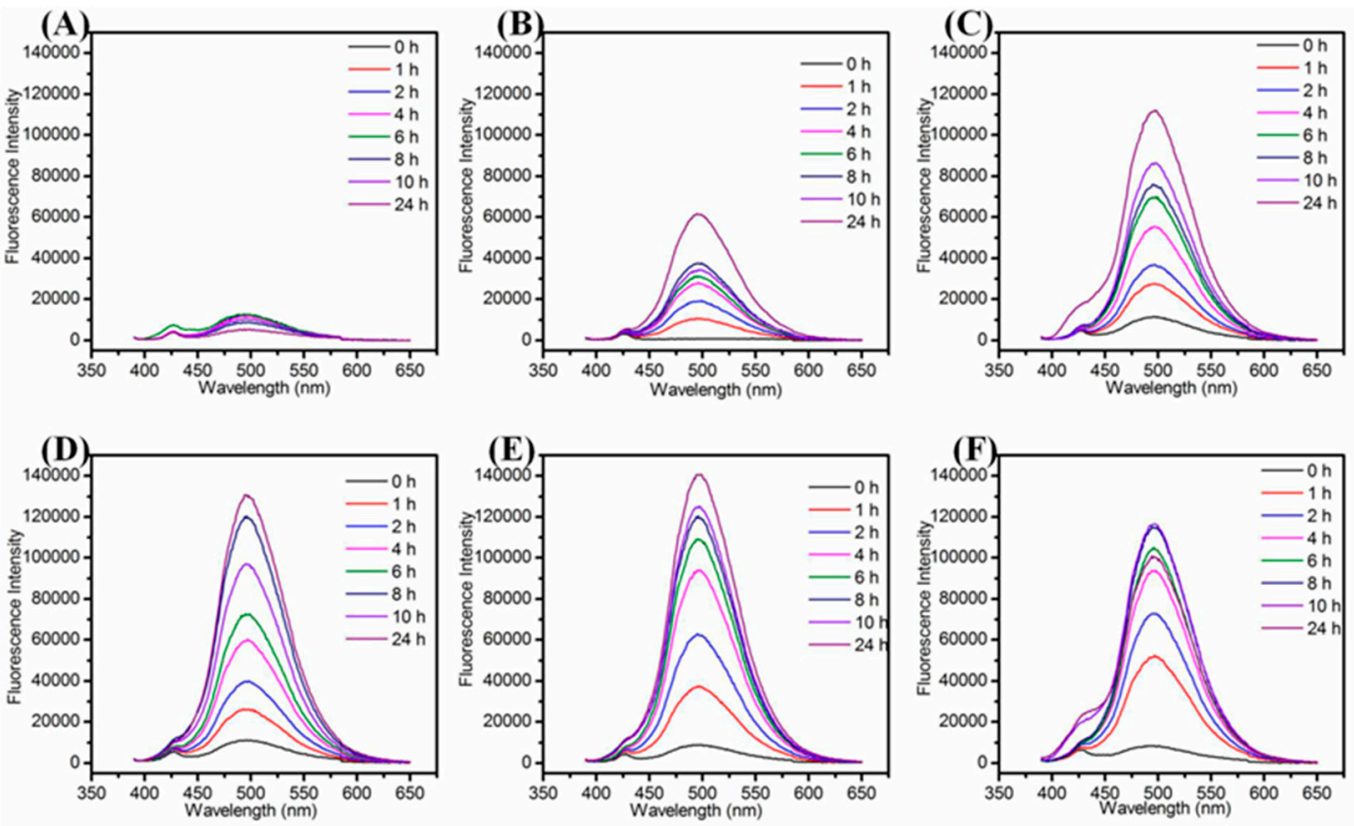

Figure 2. Fluorescence emission spectra of $\mathrm{Cu}$ NCs@GSH with the reaction time under different heating temperatures. (A) $25^{\circ} \mathrm{C}$; (B) $50{ }^{\circ} \mathrm{C}$; (C) $60{ }^{\circ} \mathrm{C}$; (D) $70{ }^{\circ} \mathrm{C}$; (E) $80^{\circ} \mathrm{C}$; (F) $90{ }^{\circ} \mathrm{C}$ ).

\subsection{Characterization of As-Prepared Cu NCs@GSH}

The as-synthesized $\mathrm{Cu}$ NCs@GSH were well dispersed in water and emitted an intense blue-green fluorescence under $365 \mathrm{~nm}$ irritation (Figure 3D). Figure 3A shows that the maximum excitation wavelength and emission wavelength are located at $372 \mathrm{~nm}$ and $497 \mathrm{~nm}$, respectively. Meanwhile, as the blank control, the pure $\mathrm{Cu}^{2+}$, pure GSH and their mixture show no fluorescence (Figure S2). In Figure 3B, there is an obvious absorption peak around $600 \mathrm{~nm}$, which may be attributed to the aggregation of Cu NCs@GSH (in Figure S3) and not the formation of large size Cu NPs. The location of emission peak remained unchanged even upon various excitation wavelengths (Figure 3C), implying that it was real fluorescence and not light scattering [43-45] and the relatively uniform surface state $[46,47]$. After freeze-drying, the lavender powder was obtained, which showed no fluorescence by irradiating at $365 \mathrm{~nm}$ while the strong blue-green fluorescence of $\mathrm{Cu}$ NCs@GSH can be recovered after their redispersion in water (Figure S4). The QY of as-prepared Cu NCs@GSH in aqueous solution was calculated to $6.2 \%$ using quinine sulfate $\left(\mathrm{QY}=0.54\right.$ in $\left.1 \mathrm{M} \mathrm{H}_{2} \mathrm{SO}_{4}\right)$ as the reference [48]. It was also observed that by dispersing the $\mathrm{Cu}$ NCs in ethanol aqueous mixture, with increasing volume ratio of ethanol to water, the fluorescence intensity was gradually enhanced by increasing ethanol content (Figure S5), indicating that the Cu NCs@GSH exhibit the aggregation-induced emission enhancement (AIEE), which agrees with previous reports [49-52]. More important, the as-synthesized Cu NCs@GSH exhibited excellent stability (Figure 4).

As shown in Figure 4A, the fluorescence intensity of $\mathrm{Cu}$ NCs remained the same even in the solution with high ionic strength. The $\mathrm{Cu}$ NCs also exhibited good resistance to oxidation for that the addition of $\mathrm{H}_{2} \mathrm{O}_{2}$ influenced the fluorescence intensity very slightly (Figure $4 \mathrm{~B}$ ). After exposure to 372-nm excitation light for $7000 \mathrm{~s}$, the fluorescence intensity of $\mathrm{Cu}$ NCs decreased by 13.4\%, exhibiting better photostability than that organic dye Rhodamine 6G (Figure 4C). The storage under $4{ }^{\circ} \mathrm{C}$ for 3 months and 6 months reduced the fluorescence intensity of $\mathrm{Cu}$ NCs only by $5.5 \%$ and $16.5 \%$, respectively, exhibiting their decent stability over a long period of time that would be very beneficial for their potential bio-applications (Figure 4D). 
(A)

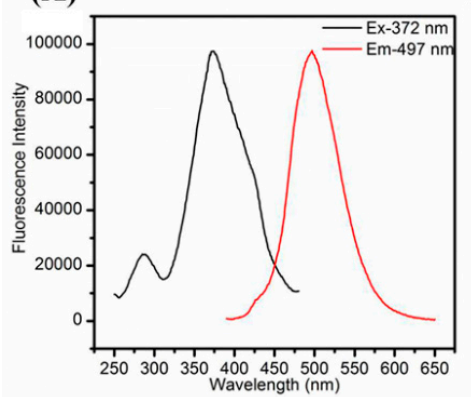

(C)

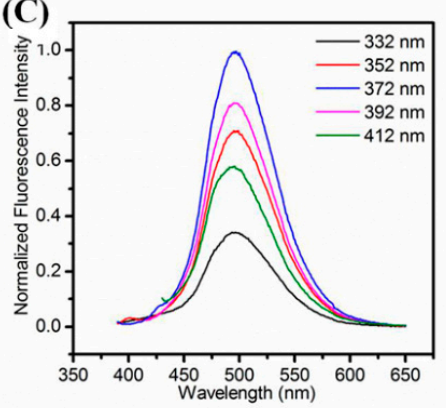

(B)

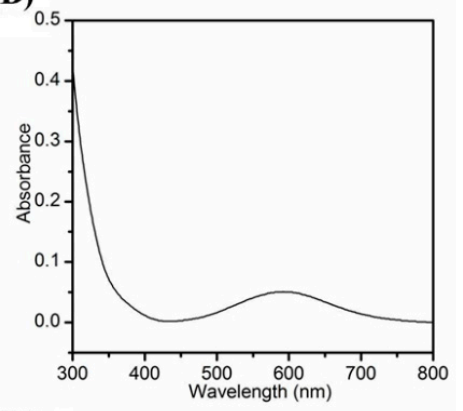

(D)

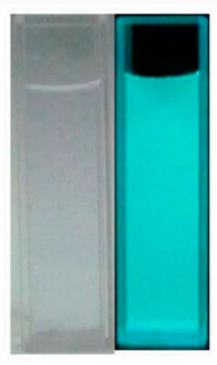

Figure 3. (A) Fluorescence excitation and emission spectra. (B) UV-vis absorption spectra; (C) normalized fluorescence emission spectra the Cu NCs@GSH upon various excitation wavelengths ranging from $332 \mathrm{~nm}$ to $412 \mathrm{~nm}$; (D) photograph of Cu NCs@GSH under daylight and 365-nm UV light.
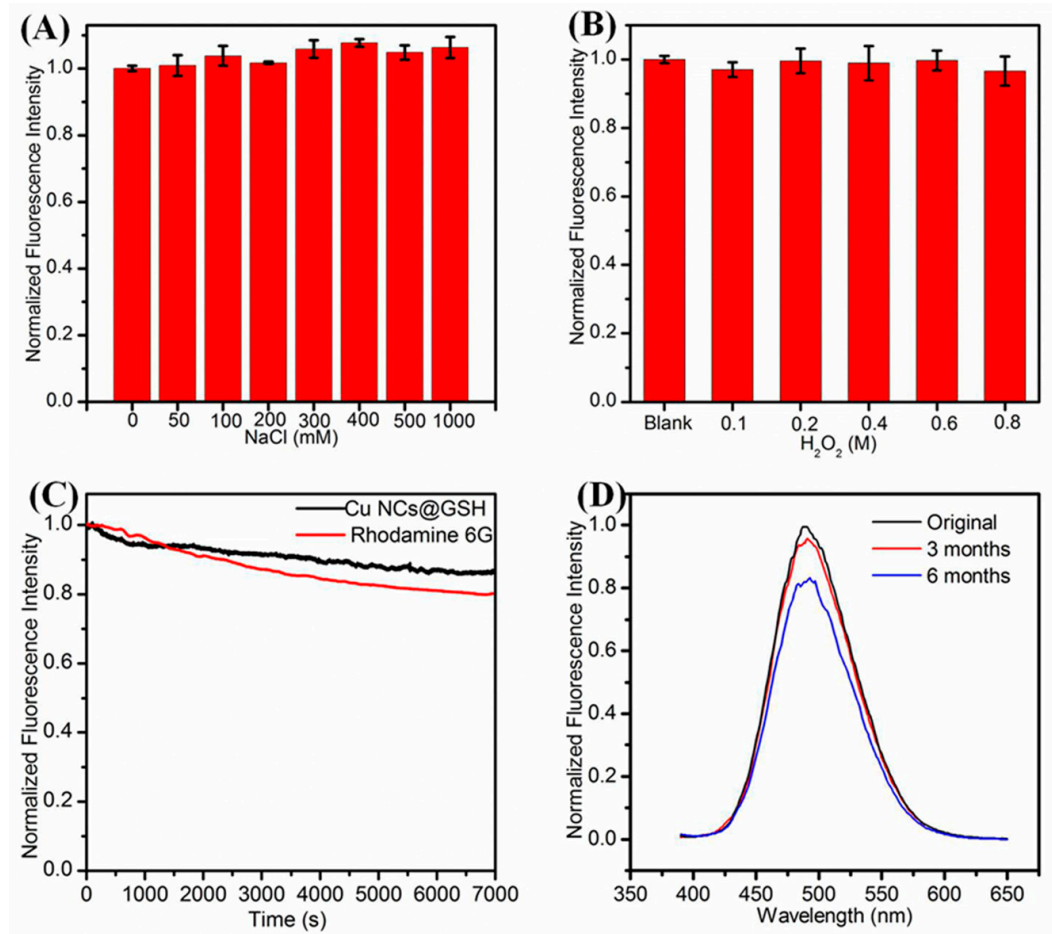

Figure 4. Effect of (A) Ionic strength; (B) concentration of $\mathrm{H}_{2} \mathrm{O}_{2} ;$ (C) irradiation time; (D) storage time on the fluorescence intensity of $\mathrm{Cu}$ NCs.

The FTIR spectrum shows a typical absorption band of the carboxyl group at $1712 \mathrm{~cm}^{-1}$ that corresponds to the weak interaction of the glycine residues of GSH with $\mathrm{Cu}$ NCs (Figure 5A). Compared with the pure GSH alone, the characteristic peak of SH at $2525 \mathrm{~cm}^{-1}$, disappeared in the GSH-stabilized $\mathrm{Cu}$ NCs, suggesting the interaction between thiol group and Cu NCs [49]. XPS analysis showed that the binding energy of $\mathrm{Cu} 2 \mathrm{p}_{3 / 2}$ and $\mathrm{Cu} 2 \mathrm{p}_{1 / 2}$ were located at $932.9 \mathrm{eV}$ and $952.4 \mathrm{eV}$ (Figure 5B) indicating that $\mathrm{Cu} N C s$ are indeed composed of both $\mathrm{Cu}(0)$ and $\mathrm{Cu}(\mathrm{I})$ species, and the 
existence of $\mathrm{Cu}(\mathrm{I})$ also supports their improved stability and quantum yield [23,24]. Furthermore, there was no peak displayed around $942.0 \mathrm{eV}$, demonstrating the absence of $\mathrm{Cu}$ (II) in $\mathrm{Cu}$ NCs [52]. In addition, the $\mathrm{S} 2 \mathrm{p} 3 / 2$ peak located at $166.3 \mathrm{eV}$ confirmed the covalent interaction of $\mathrm{Cu}$ NCs with the $\mathrm{SH}$ group (Figure 5E) [53]. The peaks of $\mathrm{S}(1 \mathrm{~s}), \mathrm{C}(1 \mathrm{~s}), \mathrm{N}(1 \mathrm{~s}), \mathrm{Na}, \mathrm{O}(1 \mathrm{~s}), \mathrm{Cu}(2 \mathrm{p})$, and $\mathrm{Na}(1 \mathrm{~s})$ are clearly visible in the spectrum (Figure 5F), further indicating that $\mathrm{Cu}$ NCs are stabilized by GSH [54]. The exact atomic composition of $\mathrm{Cu}$ NCs was determined using ESI-MS analysis. From the MS spectrum (Figure 5C), the highest peak located at 1942.7 could be attributed to the structure composition of $\left[\mathrm{Cu}_{11}(\mathrm{GSH})_{4}+\mathrm{Na}+8 \mathrm{H}\right]$. The HRTEM image (Figure 5D) clearly showed the formation of uniform $\mathrm{Cu}$ NCs with an average diameter of $2.3 \pm 0.4 \mathrm{~nm}$.

(A)

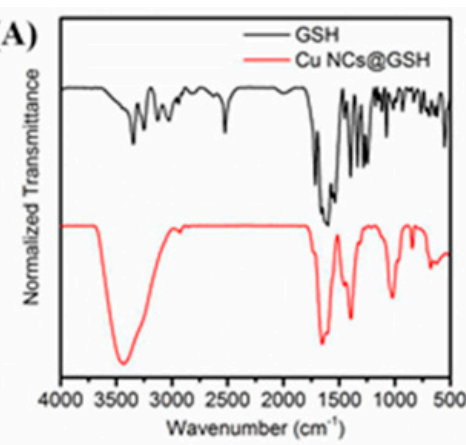

(C)

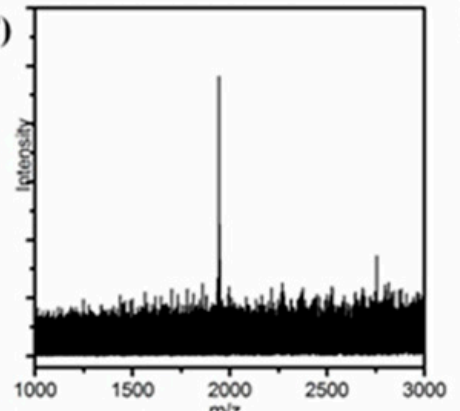

(E)

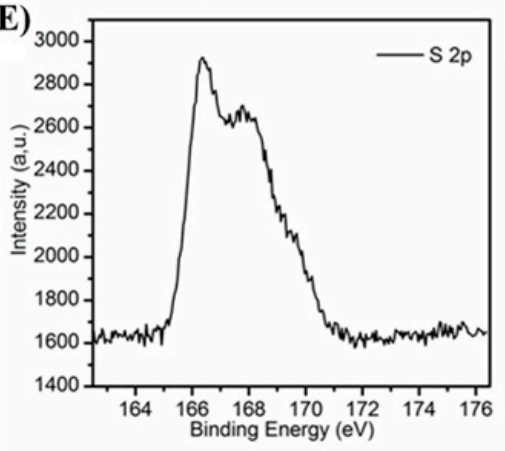

(D)
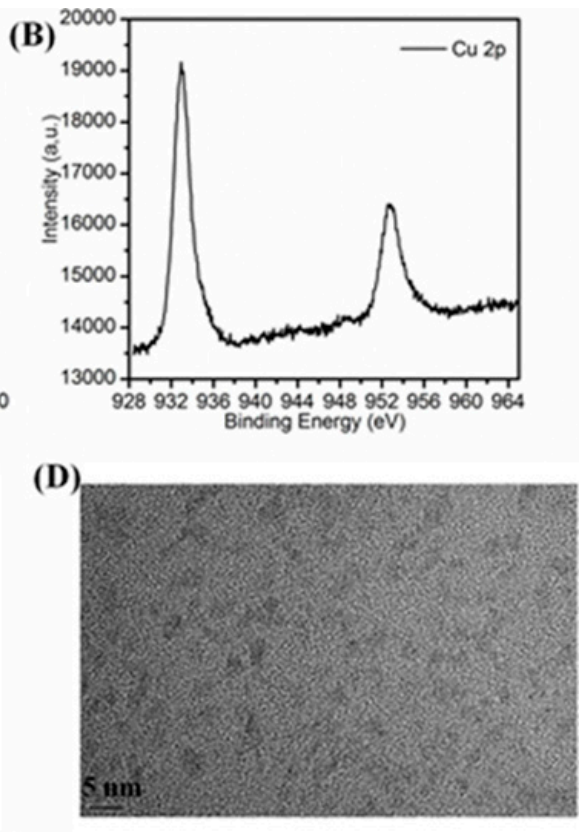

(F)

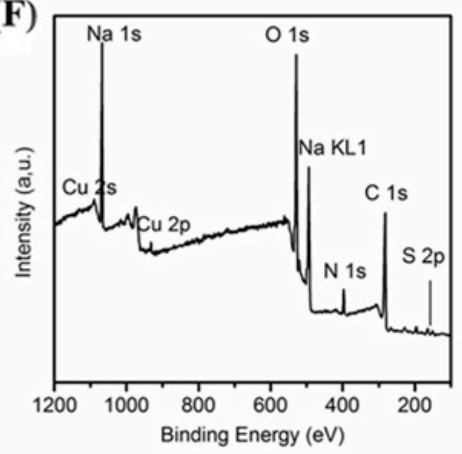

Figure 5. (A) Infrared spectra of the as-prepared Cu NCs@GSH and GSH; (B) Cu 2p XPS spectrum; (C) ESI-MS spectra; (D) HRTEM image of the as-prepared Cu NCs; (E) S 2p XPS spectrum; (F) whole XPS spectrum of the as-prepared $\mathrm{Cu}$ NCs and $\mathrm{C}(1 \mathrm{~s}), \mathrm{N}(1 \mathrm{~s}), \mathrm{O}(1 \mathrm{~s}), \mathrm{S}(2 \mathrm{p}), \mathrm{Na}(1 \mathrm{~s})$ and $\mathrm{Cu}(2 \mathrm{p})$ core-level photoemission spectra all appeared on the XPS spectrum.

\subsection{Cytotoxicity Assay and Cellular Imaging}

Prior to the biologic applications, the cytotoxicity of the Cu NCs@GSH was studied by the MTT method. As shown in Figure 6, after different concentrations of Cu NCs@GSH were incubated with HeLa cells for $12 \mathrm{~h}$, there was no obvious decrease of the cell viability, but the slight cell growth. These results clearly suggest that the Cu NCs@GSH are biocompatible and suitable for potential bioimaging applications. In order to explore the role of $\mathrm{Cu}$ NCs in the field of fluorescent bioimaging, we chose human embryonic kidney cells HEK293T in this study (Figure 7). After incubation with Cu 
NCs, all the cells showed clear cells morphology and a bright blue fluorescence from the intracellular region (Figure $7 \mathrm{~A}, \mathrm{~B}$ ), while no fluorescence was observed from the control experiment under the similar conditions (Figure S6). EB is a commonly used organic dye in tissue labeling due to its specific binding to nuclei. Comparing the images of EB-labeled HEK293T cells (Figure 7C) and the overlap of the above three images (Figure 7D), it can be seen that the $\mathrm{Cu}$ NCs were also mainly accumulated in nuclei of the cells, suggesting that the as-prepared $\mathrm{Cu}$ NCs could potentially be used as the fluorescent probe for applications in cellular imaging.

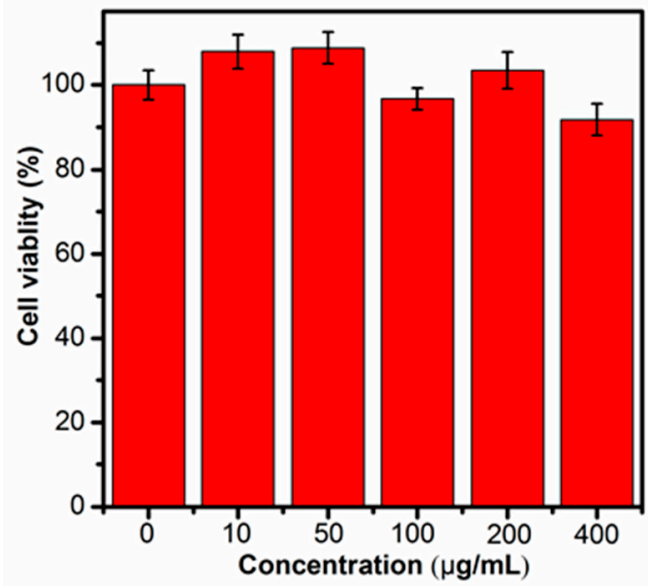

Figure 6. Viabilities after being incubated with $\mathrm{Cu}$ NCs in the concentrations range from 0 to $400 \mu \mathrm{g} / \mathrm{mL}$.

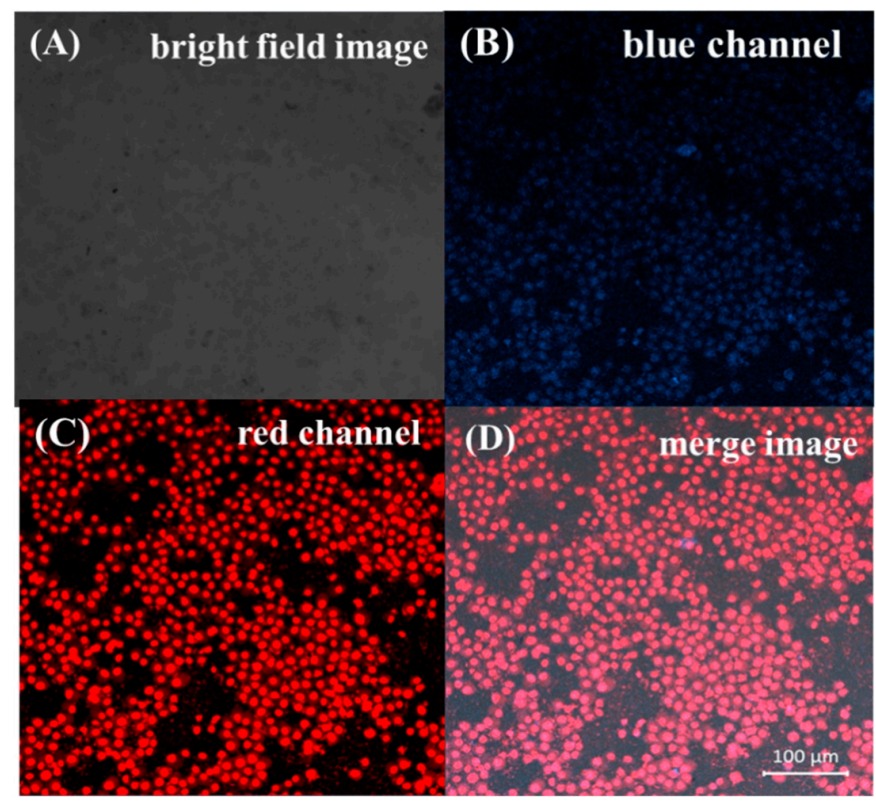

Figure 7. Confocal laser scanning microscopy images of the HEK293T cells incubated with the $\mathrm{Cu}$ NCs and then stained with EB. (A) Bright field images; (B) images of cells labeled Cu NCs at 380-nm excitation; (C) images of EB-labeled cells at 583-nm excitation; (D) overlap of the above three images.

\section{Conclusions}

In summary, a facile synthetic protocol is developed for the preparation of highly fluorescent $\mathrm{Cu}$ NCs using GSH as both a reducing and stabilizing agent, which can be upscaled easily. The as-synthesized $\mathrm{Cu}$ NCs exhibit bright blue-green fluorescence, high QY and excellent stability. Moreover, the $\mathrm{Cu}$ NCs exhibit low cytotoxicity and, therefore, possess great potential for cellular imaging to study various biologic processes. 
Supplementary Materials: The following are available online at http://www.mdpi.com/2079-4991/10/9/1678/s1. Figure S1: The photographs of Cu NCs under ordinary daylight (A) and UV-irradiation (B); Figure S2: Fluorescence emission spectra of GSH, $\mathrm{Cu}^{2+}$ solution and mixture of $\mathrm{GSH}$ and $\mathrm{Cu}^{2+}$; Figure S3: A high resolution TEM image of Cu NCs@GSH ;Figure S4: (A) Fluorescence excitation (dash line) and emission (solid line) spectra of Cu NCs@GSH in water (blue) and solid (black) state; (B) The photographs of Cu NCs@GSH solid and redispersed in water under daylight (above) and 365-nm UV light (below), Figure S5: (A) The fluorescence emission spectra and (B) Histogram of Cu NCs@GSH in different vol\% ethanol: water mixture, Figure S6: Images of HEK293T cells incubated without $\mathrm{Cu}$ NCs obtained (A) under bright field and (B) at the excitation wavelength of $380 \mathrm{~nm}$. All authors have read and agreed to the published version of the manuscript.

Author Contributions: W.Y. performed the experiments, reviewed and edited the draft; J.Z. performed the experiments and wrote the original draft; M.A. and Y.L. performed the experiments; S.Z.H. and S.M. characterized the clusters; Z.S. helped the software; B.T. and I.H. guided the experiments, reviewed the draft. All authors have read and agreed to the published version of the manuscript.

Funding: We thank the Analysis and Testing Center, Huazhong University of Science and Technology for assistance in characterization of materials. This work was supported by National Key Research and Development Project 2018YFE0117300 from Ministry of Science and Technology, National Natural Science Foundation of China (No. 51773196,21474033), Key Project of Hubei Educational Commission (D20171005), Science Technology and Innovation Seed Fund Project znpy2018033, Opening Funding from Hubei Key Laboratory of Polymer Materials, Opening Funding from Key Laboratory of Green Preparation and Application for Functional Materials, Opening Funding from Hubei Collaborative Innovation Center for Advanced Organic Chemical Materials and the Program for HUST Interdisciplinary Innovation Team (2016JCTD104).

Conflicts of Interest: The authors declare no conflict of interests.

\section{References}

1. Luo, Z.; Nachammai, V.; Zhang, B.; Yan, N.; Leong, D.T.; Jiang, D.E.; Xie, J. Toward understanding the growth mechanism: Tracing all stable intermediate species from reduction of $\mathrm{Au}(\mathrm{I})$-thiolate complexes to evolution of $\mathrm{Au}(2)(5)$ nanoclusters. J. Am. Chem. Soc. 2014, 136, 10577-10580. [CrossRef]

2. Cai, Z.; Yin, X.; Fang, J.; Zhao, J.; Wu, T.; Hao, E.; Tian, F.; Zhang, C. L-Histidine Stabilized Copper Nanoclusters as a Fluorescence Probe for Determination of Fluazinam. Nano 2020, 15, 2050063. [CrossRef]

3. Li, T.; Zhang, L.; Ai, J.; Dong, S.; Wang, E. Ion-Tuned DNA/Ag Fluorescent Nanoclusters As Versatile Logic Device. Acs Nano 2011, 5, 6334-6338. [CrossRef]

4. Liu, Y.; Ai, K.; Cheng, X.; Huo, L.; Lu, L. Gold-Nanocluster-Based Fluorescent Sensors for Highly Sensitive and Selective Detection of Cyanide in Water. Adv. Funct. Mater. 2010, 20, 951-956. [CrossRef]

5. Zhang, G.; Qiao, Y.; Xu, T.; Zhang, C.; Zhang, Y.; Shi, L.; Shuang, S.; Dong, C. Highly selective and sensitive nanoprobes for cyanide based on gold nanoclusters with red fluorescence emission. Nanoscale 2015, 7, 12666-12672. [CrossRef]

6. Li, Y.L.; Wang, Z.Y.; Ma, X.H.; Luo, P.; Du, C.X.; Zang, S.Q. Distinct photophysical properties in atom-precise silver and copper nanocluster analogues. Nanoscale 2019, 11, 5151-5157. [CrossRef]

7. Zhao, H.; Wen, X.; Li, W.; Li, Y.; Yin, C. A copper-mediated on-off-on gold nanocluster for endogenous GSH sensing to drive cancer cell recognition. J. Mater. Chem. B 2019, 7, 2169-2176. [CrossRef]

8. Wang, Z.; Chen, B.; Susha, A.S.; Wang, W.; Reckmeier, C.J.; Chen, R.; Zhong, H.; Rogach, A.L. All-Copper Nanocluster Based Down-Conversion White Light-Emitting Devices. Adv. Sci. 2016, 3, 2198-3844. [CrossRef]

9. Wang, Z.; Susha, A.S.; Chen, B.; Reckmeier, C.; Tomanec, O.; Zboril, R.; Zhong, H.; Rogach, A.L. Poly(vinylpyrrolidone) supported copper nanoclusters: Glutathione enhanced blue photoluminescence for application in phosphor converted light emitting devices. Nanoscale 2016, 8, 7197-7202. [CrossRef]

10. Chen, T.; Hu, Y.; Cen, Y.; Chu, X.; Lu, Y. A dual-emission fluorescent nanocomplex of gold-cluster-decorated silica particles for live cell imaging of highly reactive oxygen species. J. Am. Chem. Soc. 2013, 135, 11595-11602. [CrossRef]

11. Chen, W.H.; Luo, G.F.; Xu, X.D.; Jia, H.Z.; Lei, Q.; Han, K.; Zhang, X.Z. Cancer-targeted functional gold nanoparticles for apoptosis induction and real-time imaging based on FRET. Nanoscale 2014, 6, 9531-9535. [CrossRef]

12. Heo, G.S.; Zhao, Y.; Sultan, D.; Zhang, X.; Detering, L.; Luehmann, H.P.; Zhang, X.; Li, R.; Choksi, A.; Sharp, S.; et al. Assessment of Copper Nanoclusters for Accurate in Vivo Tumor Imaging and Potential for Translation. ACS Appl. Mater. Interfaces 2019, 11, 19669-19678. [CrossRef] [PubMed] 
13. Liu, H.; Andoh, V.; Cao, Z.; Tao, C.; Fan, J.; Lv, X.; Ma, L. A method for synthesizing copper nanoclusters based on protein-polyacrylamide gel and its application. J. Iran. Chem. Soc. 2020, 17, 2045-2052. [CrossRef]

14. Choi, S.; Dickson, R.M.; Yu, J. Developing luminescent silver nanodots for biological applications. Chem. Soc. Rev. 2012, 41, 1867-1891. [CrossRef] [PubMed]

15. Lu, Y.; Chen, W. Sub-nanometre sized metal clusters: From synthetic challenges to the unique property discoveries. Chem. Soc. Rev. 2012, 41, 3594-3623. [CrossRef]

16. Venkatesh, V.; Shukla, A.; Sivakumar, S.; Verma, S. Purine-stabilized green fluorescent gold nanoclusters for cell nuclei imaging applications. ACS Appl. Mater. Interfaces 2014, 6, 2185-2191. [CrossRef]

17. Feng, X.; Zhang, J.; Wang, J.; Han, A.; Fang, G.; Liu, J.; Wang, S. The stabilization of fluorescent copper nanoclusters by dialdehyde cellulose and their use in mercury ion sensing. Anal. Methods 2020, 12, 3130-3136. [CrossRef]

18. Shiang, Y.C.; Huang, C.C.; Chen, W.Y.; Chen, P.C.; Chang, H.T. Fluorescent gold and silver nanoclusters for the analysis of biopolymers and cell imaging. J. Mater. Chem. 2012, 22, 12972-12982. [CrossRef]

19. Wang, H.H.; Lin, C.A.J.; Lee, C.H.; Lin, Y.C.; Yeh, H.I. Fluorescent gold nanoclusters as a biocompatible marker for in vitro and in vivo tracking of endothelial cells. Acs Nano 2011, 5, 4337-4344. [CrossRef]

20. Yu, J.; Choi, S.; Dickson, R.M. Shuttle-based fluorogenic silver-cluster biolabels. Angew. Chem. Int. Ed. 2009, 48, 318-320. [CrossRef]

21. Cho, W.J.; Kim, Y.; Kim, J.K. Ultrahigh-Density Array of Silver Nanoclusters for SERS Substrate with High Sensitivity and Excellent Reproducibility. Acs Nano 2012, 6, 249-255. [CrossRef] [PubMed]

22. Huang, C.C.; Yang, Z.; Lee, K.H.; Chang, H.T. Synthesis of highly fluorescent gold nanoparticles for sensing mercury(II). Angew. Chem. Int. Ed. 2007, 46, 6824-6828. [CrossRef]

23. Wang, C.; Wang, C.; Xu, L.; Cheng, H.; Lin, Q.; Zhang, C. Protein-directed synthesis of pH-responsive red fluorescent copper nanoclusters and their applications in cellular imaging and catalysis. Nanoscale 2014, 6, 1775-1781. [CrossRef] [PubMed]

24. Wei, W.; Lu, Y.; Chen, W.; Chen, S. One-pot synthesis, photoluminescence, and electrocatalytic properties of subnanometer-sized copper clusters. J. Am. Chem. Soc. 2011, 133, 2060-2063. [CrossRef] [PubMed]

25. Zhao, T.; He, X.-W.; Li, W.-Y.; Zhang, Y.-K. Transferrin-directed preparation of red-emitting copper nanoclusters for targeted imaging of transferrin receptor over-expressed cancer cells. J. Mater. Chem. B 2015, 3, 2388-2394. [CrossRef]

26. Biswas, S.; Miller, J.T.; Li, Y.; Nandakumar, K.; Kumar, C.S. Developing a millifluidic platform for the synthesis of ultrasmall nanoclusters: Ultrasmall copper nanoclusters as a case study. Small 2012, 8, 687-698. [CrossRef] [PubMed]

27. Xiang, C.; Zhong, X.; Yang, W.; Majeed, M.I.; Wang, J.; Yu, J.; Hu, J.; Xu, Z.; Tan, B.; Zhang, B.; et al. Fe $\mathrm{F}_{4}$ Nanoparticles Functionalized with Polymer Ligand for T1-Weighted MRI In Vitro and In Vivo. Polymers 2019, 11, 882. [CrossRef]

28. Ouyang, X.; Wang, M.; Guo, L.; Cui, C.; Liu, T.; Ren, Y.; Zhao, Y.; Ge, Z.; Guo, X.; Xie, G.; et al. DNA Nanoribbon-Templated Self-Assembly of Ultrasmall Fluorescent Copper Nanoclusters with Enhanced Luminescence. Angew. Chem. Int. Ed. 2020, 59, 11836-11844. [CrossRef]

29. Yuan, J.; Wang, L.; Wang, Y.; Hao, J. Stimuli-Responsive Fluorescent Nanoswitches: Solvent-Induced Emission Enhancement of Copper Nanoclusters. Chem. Eur. J. 2020, 26, 3545-3554. [CrossRef]

30. Lin, L.; Hu, Y.; Zhang, L.; Huang, Y.; Zhao, S. Photoluminescence light-up detection of zinc ion and imaging in living cells based on the aggregation induced emission enhancement of glutathione-capped copper nanoclusters. Biosens. Bioelectron. 2017, 94, 523-529. [CrossRef]

31. Baghdasaryan, A.; Grillo, R.; Roy Bhattacharya, S.; Sharma, M.; Reginato, E.; Theraulaz, H.; Dolamic, I.; Dadras, M.; Rudaz, S.; Varesio, E.; et al. Facile Synthesis, Size-Separation, Characterization, and Antimicrobial Properties of Thiolated Copper Clusters. ACS Appl. Nano Mater. 2018, 1, 4258-4267. [CrossRef]

32. Chen, S.; Huang, Z.; Jia, Q. Electrostatically confined in-situ preparation of stable glutathione-capped copper nanoclusters for fluorescence detection of lysozyme. Sens. Actuators B 2020, 319, 128305. [CrossRef]

33. Jalili, R.; Khataee, A. Aluminum(III) triggered aggregation-induced emission of glutathione-capped copper nanoclusters as a fluorescent probe for creatinine. Mikrochim. Acta 2018, 186, 29. [CrossRef]

34. Qu, F.; Yang, Q.; Wang, B.; You, J. Aggregation-induced emission of copper nanoclusters triggered by synergistic effect of dual metal ions and the application in the detection of $\mathrm{H} 2 \mathrm{O} 2$ and related biomolecules. Talanta 2020, 207, 120289. [CrossRef] [PubMed] 
35. Xie, J.; Zheng, Y.; Ying, J.Y. Protein-Directed Synthesis of Highly Fluorescent Gold Nanoclusters. J. Am. Chem. Soc. 2009, 131, 888-889. [CrossRef] [PubMed]

36. Zhou, T.; Rong, M.; Cai, Z.; Yang, C.J.; Chen, X. Sonochemical synthesis of highly fluorescent glutathione-stabilized Ag nanoclusters and S2- sensing. Nanoscale 2012, 4, 4103-4106. [CrossRef] [PubMed]

37. Li, Y.; Feng, L.; Yan, W.; Hussain, I.; Su, L.; Tan, B. PVP-templated highly luminescent copper nanoclusters for sensing trinitrophenol and living cell imaging. Nanoscale 2019, 11, 1286-1294. [CrossRef]

38. Negishi, Y.; Nobusada, K.; Tsukuda, T. Glutathione-protected gold clusters revisited: Bridging the gap between gold(I)-thiolate complexes and thiolate-protected gold nanocrystals. J. Am. Chem. Soc. 2005, 127, 5261-5270. [CrossRef]

39. Zheng, K.; Yuan, X.; Kuah, K.; Luo, Z.; Yao, Q.; Zhang, Q.; Xie, J. Boiling water synthesis of ultrastable thiolated silver nanoclusters with aggregation-induced emission. Chem. Commun. 2015, 51, 15165-15168. [CrossRef]

40. Zhang, B.; Yan, W.; Zhu, Y.; Yang, W.; Le, W.; Chen, B.; Zhu, R.; Cheng, L. Nanomaterials in Neural-StemCell-Mediated Regenerative Medicine: Imaging and Treatment of Neurological Diseases. Adv. Mater. 2018, 30, 1705694. [CrossRef]

41. Shi, Y.E.; Luo, S.; Ji, X.; Liu, F.; Chen, X.; Huang, Y.; Dong, L.; Wang, L. Synthesis of ultra-stable copper nanoclusters and their potential application as a reversible thermometer. Dalton Trans. 2017, 46, 14251-14255. [CrossRef] [PubMed]

42. Zhang, J.; Cai, C.; Razzaque, S.; Hussain, I.; Lu, Q.-W.; Tan, B. Synthesis of water-soluble and highly fluorescent gold nanoclusters for $\mathrm{Fe}^{3+}$ sensing in living cells using fluorescence imaging. J. Mater. Chem. B 2017, 5, 5608-5615. [CrossRef]

43. Cao, H.; Chen, Z.; Zheng, H.; Huang, Y. Copper nanoclusters as a highly sensitive and selective fluorescence sensor for ferric ions in serum and living cells by imaging. Biosens. Bioelectron. 2014, 62, 189-195. [CrossRef] [PubMed]

44. Jeong, M.; Kim, H.M.; Lee, J.S.; Choi, J.H.; Jang, D.S. (-)-Asarinin from the Roots of Asarum sieboldii Induces Apoptotic Cell Death via Caspase Activation in Human Ovarian Cancer Cells. Molecule 2018, $23,1849$. [CrossRef] [PubMed]

45. Diana, R.; Caruso, U.; Di Costanzo, L.; Bakayoko, G.; Panunzi, B. A Novel DR/NIR T-Shaped AIEgen: Synthesis and X-Ray Crystal Structure Study. Crystal 2020, 10, 269. [CrossRef]

46. Deng, H.H.; Li, K.L.; Zhuang, Q.Q.; Peng, H.P.; Zhuang, Q.Q.; Liu, A.L.; Xia, X.H.; Chen, W. An ammonia-based etchant for attaining copper nanoclusters with green fluorescence emission. Nanoscale 2018, 10, 6467-6473. [CrossRef]

47. Han, S.; Chen, X. Copper nanoclusters-enhanced chemiluminescence for folic acid and nitrite detection. Spectrochim. Acta. A Mol. Biomol. Spectrosc. 2019, 210, 315-320. [CrossRef]

48. Li, Y.; Wang, K.-N.; Liu, B.; Lu, X.-R.; Li, M.-F.; Ji, L.-N.; Mao, Z.-W. Mitochondria-targeted two-photon fluorescent probe for the detection of biothiols in living cells. Sens. Actuators, B 2018, 255, 193-202. [CrossRef]

49. Ye, J.; Dong, X.; Jiang, H.; Wang, X. An intracellular temperature nanoprobe based on biosynthesized fluorescent copper nanoclusters. J. Mater. Chem. B 2017, 5, 691-696. [CrossRef]

50. Jia, X.; Li, J.; Wang, E. Cu nanoclusters with aggregation induced emission enhancement. Small 2013, 9, 3873-3879. [CrossRef]

51. Jia, X.; Yang, X.; Li, J.; Li, D.; Wang, E. Stable Cu nanoclusters: From an aggregation-induced emission mechanism to biosensing and catalytic applications. Chem. Commun. 2014, 50, 237-239. [CrossRef] [PubMed]

52. Vazquez-Vazquez, C.; Banobre-Lopez, M.; Mitra, A.; Lopez-Quintela, M.A.; Rivas, J. Synthesis of small atomic copper clusters in microemulsions. Langmuir 2009, 25, 8208-8216. [CrossRef] [PubMed]

53. Deng, H.H.; Wu, G.W.; Zou, Z.Q.; Peng, H.P.; Liu, A.L.; Lin, X.H.; Xia, X.H.; Chen, W. pH-Sensitive gold nanoclusters: Preparation and analytical applications for urea, urease, and urease inhibitor detection. Chem. Commun. 2015, 51, 7847-7850. [CrossRef] [PubMed]

54. Xu, S.; Gao, T.; Feng, X.; Mao, Y.; Liu, P.; Yu, X.; Luo, X. Dual ligand co-functionalized fluorescent gold nanoclusters for the "turn on" sensing of glutathione in tumor cells. J. Mater. Chem. B 2016, 4, 1270-1275. [CrossRef] [PubMed]

(C) 2020 by the authors. Licensee MDPI, Basel, Switzerland. This article is an open access article distributed under the terms and conditions of the Creative Commons Attribution (CC BY) license (http://creativecommons.org/licenses/by/4.0/). 